\title{
SERNAC FINANCIERO: FUNDAMENTOS Y PERSPECTIVAS
}

Financial Sernac: foundations and PERSPECTIVES

FinANCiÈre Sernac: FONDEMENTS ET PERSPECTIVE

JAIME LORENZINI BARRÍA*

\section{INTRODUCCIÓN}

El presente trabajo aborda la nueva regulación en materia de protección al consumidor en el ámbito de productos y servicios financieros. Esta normativa ha sido conocida como "Sernac Financiero", y establece nuevos estándares y exigencias a los proveedores del mercado financiero, particularmente, en lo relativo a nuevos deberes de información y contenidos mínimos en los contratos de adhesión y ciertos contenidos prohibidos en dichos acuerdos. Se identifican los principales aspectos de la nueva regulación, incluyendo el "Sello Sernac", junto con anticipar los desafíos que se encuentran pendientes para lograr los objetivos buscados con esta nueva regulación

\section{1. ¿Por qué Sernac Financiero?}

El Sernac Financiero se origina como una medida de respuesta a los constantes reclamos de los consumidores en el área de los productos y servicios financieros. Intentando reforzar los derechos de información y eliminar los abusos en numerosas prácticas de los proveedores en esta área del mercado, surgió la iniciativa de dotar de atribuciones específicas en materias financieras al Servicio Nacional del Consumidor (Sernac) y establecer una serie de nuevos estándares y exigencias que los proveedores debían necesariamente cumplir. De esta manera se aseguraría un mercado más transparente, lo que es de alta relevancia considerando la necesidad que tiene la mayoría de la población en orden a acceder al crédito como mecanismo de financiamiento.

La idea de generar un nuevo marco normativo se constituyó como parte importante de la agenda política del candidato que luego se transformaría en Presidente de la República el año 2010. La justificación a la necesidad de legislar se fundamentó principalmente en la cantidad de reclamos que tenía el mercado bancario-financiero, liderando los rankings junto a otras industrias tales como retail, telecomunicaciones y transportes ${ }^{1}$.

*Abogado. Profesor de Derecho del Consumidor. Facultad de Derecho, Universidad de Chile.

${ }^{1}$ Servicio Nacional del Consumidor. Gestión 2005-2010 y Perspectivas de futuro. Disponible en: <http:// www.SERNAC.cl/acercade/Cuenta\%20de\%20gestión\%202005-2010.pdfs [consulta: 11 mayo 2012]. 
Dentro del área financiera, los reclamos se fundamentaban principalmente en el incumplimiento de las cláusulas contractuales, el desconocimiento de las condiciones de contratación y/o de información relevante, cobros indebidos y políticas abusivas en materia de cobranza extrajudicial. Todos estos aspectos requerían una revisión urgente por parte de la autoridad y un marco legal adecuado que ayudara a paliar la grave asimetría de información existente entre el consumidor y el proveedor de productos y servicios financieros.

Esta asimetría de información, constatada siempre entre consumidores y proveedores, se acrecienta en el mercado financiero atendida su complejidad. La persona que accede a un crédito debe enfrentarse a una serie de términos técnicos y prácticas comerciales asociadas a este mercado. Todo ello dificulta el entendimiento del consumidor y demuestra la necesidad de contar con herramientas que le entreguen mayor y adecuada información para tomar la mejor decisión de consumo.

Ya en la Cuenta de la Gestión del Sernac del año 2005 a 2010, el Director Nacional del Servicio de la época identificaba que los reclamos recibidos contra proveedores que comercializaban productos crediticios representaba uno de cada cuatro del universo total de reclamos formulados por los consumidores ante este organismo. Señaló en aquella oportunidad que las principales malas prácticas o espacios de desprotección identificados eran las dificultades en el acceso a la información relevante del crédito por parte de los consumidores, los cambios unilaterales en las condiciones de contratación, el cargo de cobros indebidos y el otorgamiento del crédito a una persona distinta de aquella que lo solicitaba por negligencias en la verificación de la identidad ${ }^{2}$.

También fueron claves, como antecedentes relevantes del desequilibrio de este mercado, algunos casos emblemáticos que se entablaron por infracciones a la Ley de Protección al Consumidor (en adelante LPC), pero que mostraban ya la necesidad de regular de manera específica la conducta de los proveedores en el mercado financiero. Entre ellos se puede citar la demanda que entabló Sernac contra Cencosud Administradora de Tarjetas S.A. el año 2006 relativa a infracciones a la LPC al contener una cláusula en el contrato que habilitaba a la empresa a modificar unilateralmente el mismo (dando aviso al consumidor), transgrediendo no sólo la norma que establece la abusividad de este tipo de cláusula en el artículo 16 a) de la LPC, sino que vulnerando el derecho a información veraz y oportuna que tienen todos los consumidores de acuerdo a lo señalado en el artículo $3^{\circ}$ letra b) de la LPC y el derecho a la libre elección del bien o servicio consagrado en el mismo cuerpo legal en el artículo $3^{\circ}$ letra a).

En el caso en comento, Cencosud comunicó a sus clientes la modificación que sufriría la comisión mensual por mantención de su tarjeta, mediante un inserto de tal comunicación en los estados de cuenta mensuales de los clientes, lo que 
fue considerado una infracción a la normativa vigente por parte de la Corte de Apelaciones ${ }^{3}$.

Otro caso que merece referencia es el juicio colectivo iniciado por Conadecus el año 2004 en contra del Banco Estado por el supuesto cobro improcedente de comisiones por mantención de las cuentas de ahorro de los clientes del mencionado banco. Específicamente, en diciembre del año 2002 el Banco Estado adoptó la decisión de efectuar el cobro de una comisión de mantención equivalente a $\$ 133$ mensuales, cobro que aplicaría hacia futuro, previo aviso a los ahorrantes de las cuentas de ahorro a la vista. Este cobro no se contemplaba en los contratos originalmente suscritos por lo que, al igual que el caso señalado anteriormente, significaba una modificación unilateral del contrato.

Por último, no puede dejar de mencionarse el caso La Polar que remeció al mercado financiero el año 2011. En este caso el Sernac demandó colectivamente a la empresa al constatar la práctica de realizar repactaciones unilaterales en virtud de un mandato contenido en el contrato, que además le otorgaba la facultad discrecional de aceptar estas renegociaciones. Estas repactaciones determinaron un aumento excesivo de las deudas contraídas por los clientes, quienes desconocían las repactaciones y nuevas condiciones del crédito. La demanda se entabló por infracción al derecho de información veraz y oportuna que tienen los clientes y por considerar que esta práctica genera un desequilibrio importante en perjuicio de los consumidores.

Si bien los casos anteriores se iniciaron por infracciones a la normativa general de Protección al Consumidor, no es menos cierto que, atendidas sus características, alertaron al legislador en orden a la necesidad de contar con reglas específicas en la materia que protegieran al consumidor financiero, quien no tiene otra alternativa que acceder al crédito bajo las condiciones que ofrezca el proveedor del respectivo producto o servicio financiero.

Adicionalmente, un antecedente importante para la regulación del mercado financiero fue el ingreso de Chile a la Organización para la Cooperación y el Desarrollo Económico (OCDE) a través de la firma del respectivo convenio de adhesión en enero del año 20104. Esto determinó que los estándares en diversos ámbitos de la economía se elevaran, lo que incluye específicamente las relaciones de consumo. Es más, el Sernac señaló expresamente que para ingresar a la OCDE, Chile -a través de distintas instituciones de Gobierno- debió pasar por varias pruebas según los temas a evaluar, por ejemplo, transparencia, políticas medioambientales y protección al consumidor. En este último aspecto los desafíos futuros se centran en la seguridad de productos y en la protección de los consumidores en los ámbi-

\footnotetext{
${ }^{3}$ Corte de Apelaciones de Santiago, 3 octubre 2011. Rol 976-2011.

${ }^{4}$ OCDE. Convenio de adhesión. Disponible en: <http://www.oecd.org/dataoecd/41/11/44381035.pdf> [consulta: 13 junio 2012].
} 
tos de comercio electrónico y créditos ${ }^{5}$. La promulgación del Sernac Financiero constituye una buena señal en orden a cumplir los compromisos asumidos por nuestro país ante la comunidad internacional dando claras muestras de querer mejorar el funcionamiento del mercado.

\section{2. ¿Qué es el Sernac Financiero?}

El Sernac Financiero, como se conoce a la Ley No 20.555 (Boletín No 7094), constituye un marco legal que dota de nuevas atribuciones al Sernac y establece nuevas exigencias para los proveedores de servicios y productos financieros. Estas nuevas disposiciones rigen a todo el mercado de servicios crediticios, de seguros y de cualquier otro producto financiero, ya se trate de bancos, sociedades de apoyo al giro, establecimientos comerciales, compañías de seguros, instituciones financieras, cajas de compensación, cooperativas de ahorro y crédito y cualquier otro proveedor de productos y servicios de naturaleza financiera.

Las principales modificaciones apuntan a consagrar derechos específicos para el consumidor de productos y servicios financieros y obligaciones para el proveedor de los mismos, entre ellas una serie de nuevos requisitos para los contratos de adhesión en el rubro. Adicionalmente aumentan las sanciones para infracciones en esta área y se crea el llamado "Sello Sernac", el cual se tratará más adelante, entre otras nuevas facultades del Sernac.

Antes de detallar algunas de estas modificaciones, se debe tener presente que el Sernac Financiero no es más que un compendio de normas en materia financiera que se incorporan a la LPC como estándares elevados para esta industria, sin ser un régimen legal alternativo, sino que una serie de disposiciones específicas en la materia que se aplican adicionalmente a las normas generales sobre protección del consumidor existentes desde el año 1997 en nuestro ordenamiento jurídico. Así, formar parte del mercado financiero determina la aplicación de estos mayores estándares de información, lo que no excluye jamás la aplicación de las demás disposiciones que regulan la relación básica entre un consumidor y un proveedor profesional de la LPC y no sólo en aquellas materias vinculadas directamente al crédito, como serían los contratos de adhesión y las disposiciones en materia de cobranza extrajudicial, sino también aquellas normas que regulan toda relación de consumo como publicidad, garantías, contratación a distancia o el mismo procedimiento colectivo, entre otros aspectos.

Como se señaló anteriormente, la nueva normativa establece una serie de nuevos derechos para los consumidores financieros. Entre ellos destaca el acceso a la información acerca del costo total del producto financiero y la "carga anual equivalente”. Además, se consagra el derecho del consumidor de acceder de ma-

\footnotetext{
5 SERnAC. Disponible en: <http://www.SERNAC.cl/consejos/detalle.php?id=2363> [consulta:13 junio 2012].
} 
nera previa a las condiciones objetivas para el otorgamiento del crédito, las cuales deben ponerse a su disposición por parte del proveedor respectivo. Por último, un derecho importante es el de conocer la liquidación total de su crédito para lo cual el proveedor deberá entregar esta información, ya sea a solicitud del cliente o enviando periódicamente la misma al consumidor aun no habiendo sido requerida por éste.

Dentro de las nuevas obligaciones de los proveedores se consagra la necesidad de incorporar en los contratos de adhesión una serie de cláusulas mínimas que pretenden solucionar aspectos claves de la relación de consumo. Así, los contratos deben incorporar un desglose pormenorizado de todos los precios, cargos o comisiones que expliquen el valor efectivo de los servicios, y si consideran cargos o comisiones por uso o mantención deberán especificar claramente sus montos, periodicidad y mecanismos de reajuste, los que deberán basarse siempre en condiciones objetivas, que no dependan del solo criterio del proveedor y que sean directamente verificables por el consumidor.

Adicionalmente, se establece la obligación de contar con una serie de nuevos documentos contractuales, como la "hoja resumen" que contiene las principales cláusulas del contrato para el mejor entendimiento del consumidor y para facilitar su acceso a la información, y una serie de anexos en caso de contar con productos o servicios conexos al contrato principal y también para informar al consumidor de la existencia de un servicio de atención al cliente, en caso que la respectiva empresa cuente con uno.

Cabe destacar que el Sernac Financiero establece otras reglas transversales como la obligación de informar el precio y características relevantes del producto o servicio en la página web de la empresa si es que ésta promociona el bien o servicio por este medio. También se debe informar la carga anual equivalente en toda publicidad en que se informe la cuota o tasa del crédito. De gran importancia son también la prohibición de ventas atadas y la nueva regulación que opera en materia de mandatos, señalando que éstos deben ser siempre revocables, no pueden ser de una amplitud tal que se consideren en blanco y el proveedor debe siempre rendir cuenta de los encargos efectuados.

Por último, se debe tener presente que el Sernac Financiero impone la obligación a los proveedores de modificar sus contratos vigentes en orden a adecuarlos a la nueva normativa en todas aquellas materias que no afecten la esencia de los derechos adquiridos bajo el régimen legal anterior. Para ello, los proveedores deben enviar un anexo a sus clientes detallando las modificaciones efectuadas.

\section{Sello Sernac}

Sin perjuicio de cumplir con las disposiciones generales que se han dictado en la materia y que rigen a todo proveedor financiero sin distinción, existe la alternativa adicional de optar a la obtención de un Sello que otorgará la autoridad a quienes acrediten el cumplimiento de las exigencias legales, específicamente en 
materia de contratos de adhesión y servicio de atención al cliente. En este sentido, la ley establece que el Sernac deberá otorgar un Sello Sernac a los contratos de adhesión de bancos e instituciones financieras, establecimientos comerciales, compañías de seguros, cajas de compensación, cooperativas de ahorro y crédito y otros proveedores de servicios crediticios, de seguros y, en general, de cualquier producto o servicio financiero, cuando dichas entidades lo soliciten, demostrando el cumplimiento de ciertas condiciones.

De esta manera, el Sernac ha definido el Sello como aquel "certificado" que entregará el Sernac a aquellos contratos que haya revisado y verificado que cumplen con la Ley y que por ejemplo, no contienen alguna cláusula que pueda ser abusiva ${ }^{6}$. Por su parte el Reglamento sobre Sello Sernac lo define como: "La distinción otorgada mediante resolución exenta del Director del Sernac a un contrato de adhesión, en virtud de la constatación previa efectuada por el Sernac de que se cumplen las condiciones previstas en la Ley de Protección del Consumidor para su otorgamiento, que recae en uno o más de los productos o servicios financieros que se enumeran a continuación: a) Tarjeta de crédito; b) Tarjeta de débito; c) Cuenta corriente; d) Cuenta vista; e) Linea de crédito; f) Cuenta de ahorro; g) Crédito hipotecario; h) Crédito de consumo; y i) Condiciones generales y condiciones particulares de los contratos colectivos de seguros de desgravamen, cesantía, incendio y sismo, asociados a los productos y servicios financieros indicados en los números anteriores, sea que se encuentren o no sujetos al régimen de depósito de modelos de pólizas, conforme a lo dispuesto en la letra e) del artículo $3^{\circ}$ del decreto con fuerza de ley No 251 del Ministerio de Hacienda, de 1931".

Con la dictación de los Reglamentos para optar al Sello Sernac se fijaron los requisitos y especificaciones de la solicitud y los documentos que deben acompañarse a la misma.

No debe entenderse que esta certificación aplica a todas las empresas que mantienen buenos estándares en su relación con los consumidores. El Sello Sernac es un incentivo aplicable exclusivamente a las empresas que comercialicen productos y servicios financieros y se ha establecido precisamente a propósito de la dictación de la Ley No 20.555. Se desconoce si en el futuro la autoridad buscará reconocer las mejores políticas de protección al consumidor en empresas de otros rubros (transporte, turismo, alimentos, entre otras), pero por el momento se aplica sólo a empresas que comercializan productos y servicios financieros, aun cuando la autoridad no ha definido con precisión las empresas que quedan comprendidas bajo la noción de "empresa que comercializa productos y servicios financieros"7.

${ }^{6}$ Sernac Financiero. Disponible en: <http://www.SERNACfinanciero.cl/Sello-SERNAC/> [consulta: 13 junio 2012].

${ }^{7}$ Sin perjuicio de ello, el artículo 2 del Reglamento citado se aplica a los contratos de adhesión de bancos e instituciones financieras, establecimientos comerciales, compañías de seguros, cajas de compensación, cooperativas de ahorro y crédito y otros proveedores de servicios crediticios y, en general, de cualquier producto financiero. 
Tal como fue señalado, esta certificación es otorgada por el Sernac luego de la evaluación de los antecedentes aportados por el proveedor. Cabe destacar que en la Historia de la Ley No 20.555 existió una indicación tendiente a radicar el otorgamiento del Sello en manos de una empresa de auditoría independiente. Sin embargo, se determinó que el espíritu del proyecto de ley era, precisamente, el fortalecimiento de las facultades del organismo protector de los derechos de los consumidores en materia financiera, dotándolo en el caso particular, de la potestad de otorgar el Sello, siempre que se acreditara el cumplimiento de las exigencias legales (H. Senador Zaldívar). Además, se señaló que el examen de los antecedentes de los proveedores por auditores no constituía garantía de independencia, como se observó con las clasificadoras de riesgo, en el caso La Polar (H. Senador Tuma). Finalmente la indicación en comento se declaró inadmisible por guardar relación con la administración financiera y presupuestaria del Estado, materia de iniciativa exclusiva del Presidente de la República, de conformidad con lo dispuesto en el artículo 65, inciso tercero, de la Constitución Política de la República ${ }^{8}$.

Tratándose de empresas reguladas por las disposiciones de Ley No 20.555, la propia normativa deja entrever que para otorgar el Sello Sernac, la autoridad constatará el cumplimiento de tres condiciones generales, detalladas en el artículo 55. En primer lugar, el Sernac debe constatar que todos los contratos de adhesión que ofrezca la empresa se ajustan a la ley y a las disposiciones reglamentarias expedidas conforme a ella. Para ello, el proveedor respectivo deberá someter sus documentos contractuales a la revisión de la autoridad quien certificará mediante el Sello, que los referidos antecedentes carecen de disposiciones abusivas o que generen desequilibrios importantes entre las partes de la relación de consumo.

En segundo lugar, la ley se ha preocupado de los consumidores asegurando la existencia de adecuados canales de comunicación con la empresa. En este sentido, para optar al Sello Sernac, el proveedor debe contar con un Servicio de Atención al Cliente (en adelante SAC) que atienda las consultas y reclamos de los consumidores. En este aspecto, la ley busca definir una metodología de atención que contemple, al menos, los canales de acceso, antecedentes requeridos y otros aspectos relevantes para acceder al SAC; los tiempos de respuesta promedio de la empresa, y los mecanismos de comunicación con el cliente para entregar respuesta a sus requerimientos. Para el correcto análisis que debe efectuar la autoridad, la empresa debe acompañar a su solicitud de obtención del Sello y, adicionalmente a sus antecedentes contractuales, un documento donde conste el protocolo definido para la atención de clientes y defina el funcionamiento práctico del SAC de acuerdo a las políticas internas definidas por la empresa.

La correcta implementación y funcionamiento de un Servicio de Atención al Cliente también se vincula con el tercer aspecto clave en el otorgamiento del

${ }^{8}$ Historia de la Ley No 20.555, Biblioteca del Congreso Nacional, p. 409. Disponible en: <http://www. leychile.cl/Navegar?idNorma=1032865\&buscar=20555> [Consulta: 13 junio 2012]. 
Sello Sernac, cual es que la empresa adscriba a un sistema de mediadores o árbitros financieros que resuelvan las controversias, quejas o reclamaciones, en el caso de que el consumidor considere que el servicio de atención al cliente no ha respondido satisfactoriamente sus consultas o reclamos por cualquier producto o servicio financiero del proveedor que se otorgue en virtud de un contrato de adhesión de los regidos por la ley.

Si bien la normativa señala aspectos específicos que revisará minuciosamente la autoridad para el otorgamiento del Sello (contratos de adhesión y SAC, específicamente), no es menos cierto que para entregar esta certificación, es previsible que el Sernac analizará las prácticas de la empresa solicitante con el objeto de verificar el mejor cumplimiento de estándares adecuados a las disposiciones generales de la LPC en aspectos tales como cobranzas extrajudiciales, publicidad y promociones, juicios por infracción a la LPC, y otros temas que pueden determinar numerosos reclamos y/o denuncias por parte de los consumidores, sentando un mal precedente a ojos de la autoridad para entregar su respaldo mediante el Sello si verifica la existencia de malas prácticas. De ahí que las empresas que deseen optar a esta certificación deban mantener sus prácticas acordes a los estándares de protección al consumidor en todas las áreas que mantengan operativas y no sólo en aquellas especialmente reguladas por las nuevas disposiciones para optar a la certificación y poder mantenerla en el tiempo.

Si la empresa estima adecuadas sus políticas presentará la respectiva solicitud de obtención del Sello ante el Sernac junto a los documentos requeridos. La autoridad debe revisar los antecedentes acompañados y determinar si otorga o rechaza la certificación en un plazo máximo de 60 días contados desde la fecha de recepción del contrato respectivo (en algunos casos se puede extender hasta por 180 días). Si el Sernac no cumple con el plazo, el proveedor contará con Sello Sernac por el solo ministerio de la ley.

Como consta en la Historia de Ley No 20.555, esta solución consagra el denominado "silencio positivo", norma que constituye una excepción a la regla general de la Ley sobre Procedimientos Administrativos, que es la del "silencio negativo", esto es, que ante la falta de pronunciamiento del órgano administrativo se entiende denegada la petición de un particular y éste tiene derecho a recurrir a tribunales?.

Esta norma no estuvo exenta de discusiones, ya que hubo quienes consideraron correcto contemplar una disposición de estas características imponiendo al Sernac la obligación de actuar con la celeridad debida en un mercado dinámico, exponiendo al Director del Servicio a las sanciones que correspondan (Ministro de Economía, Fomento y Turismo; H. Senador Pérez Varela, H. Senador Tuma). Sin embargo, otros (H. Senador Zaldívar; H. Senador García) consideraron peligroso otorgar el

${ }^{9}$ Ibíd., p. 312. 
Sello en razón del solo silencio, toda vez que queda comprometida la responsabilidad del Estado y podría resultar vulnerada la confianza de los consumidores.

Esto se vincula a la gran ventaja de contar con el Sello Sernac, al tener una certificación de la autoridad que los consumidores tomarán como garantía de calidad del proveedor respectivo, entregando más fácilmente su confianza por haberse determinado que las condiciones de contratación no contemplan cláusulas abusivas y se cuenta con un adecuado servicio de atención al cliente que atenderá sus consultas y reclamos, facilitando árbitros y/o mediadores en caso de disconformidad con la solución propuesta por la empresa.

Sin embargo, se debe tener siempre presente que el Sello Sernac no es garantía de inmunidad para el proveedor, ya que los consumidores podrán siempre, mientras no prescriban sus derechos, recurrir a los tribunales de justicia con el objeto de declarar la nulidad de una o más cláusulas del contrato respectivo. Esta nulidad se solicita bajo el supuesto que la cláusula o cláusulas respectivas no cumplen con los requisitos exigidos para los contratos de productos y servicios financieros (artículo 17 B LPC), además de la nulidad que cualquier consumidor puede solicitar respecto de la aplicación de cláusulas que puedan tener carácter abusivo de acuerdo al catálogo general de cláusulas abusivas contemplado en el artículo 16 de la LPC. El Sello tampoco evita la aplicación de multas por infracciones a lo dispuesto en la ley, ya que el consumidor o Sernac podrán siempre denunciar estas infracciones.

Además de los beneficios para la imagen de la empresa que se anticipan con la obtención del Sello Sernac existe en la materia una disposición que, en la práctica, puede generar enormes beneficios para el proveedor, especialmente considerando la necesidad de identificar contingencias y falencias que pueden derivar, eventualmente, en mayores reclamos o, incluso, en juicios colectivos. Se trata del artículo 56 G de la nueva normativa que dispone la obligación para aquellas empresas que cuenten con Sello Sernac de informar a los administradores y/o directorio de la empresa (si se trata de una Sociedad Anónima) al menos trimestralmente la información relativa a los reclamos recibidos, los acuerdos suscritos por las partes en las mediaciones efectuadas y las sentencias definitivas de los árbitros financieros que les hayan sido notificadas ${ }^{10}$.

Si bien la obligación puede significar la implementación de sistemas rigurosos de registros y mantención actualizada de bases de datos, se anticipan enormes ventajas en su cumplimiento. En función de ella, los directivos de empresas que comercializan productos y servicios financieros deberán, necesariamente, estar al

\footnotetext{
${ }^{10}$ El referido artículo $56 \mathrm{G}$ establece: "Los servicios de atención al cliente deberán comunicar a los administradores de los proveedores señalados en este Título y, en el caso de proveedores constituidos como sociedades anónimas, a su directorio, al menos trimestralmente, una cuenta sobre los reclamos recibidos, los acuerdos suscritos por las partes en las mediaciones efectuadas y las sentencias definitivas de los árbitros financieros que les hayan sido notificadas".
} 
tanto de los puntos que presentan mayor grado de conflictividad, lo que permitirá elaborar estrategias de mitigación que puedan alertar y detener futuros reclamos o contingencias por iguales conceptos. Esto resulta altamente relevante desde el punto de vista del freno que pueda poner la empresa a conductas que potencialmente derivarían en juicios colectivos, máxime considerando que la información debe ser comunicada a los administradores o directorio de la empresa, quienes son los que, en definitiva, tienen la facultad de tomar las decisiones comerciales y modelar las políticas básicas que seguirá la empresa en determinadas materias.

\section{Sanciones Que conlleVa la infracción a las Reglas del Sernac Financiero y nUeVas facultades del Sernac}

La inobservancia de las obligaciones que establece la nueva regulación que se impone a los proveedores de productos y servicios financieros acarrea la aplicación de multas de acuerdo a las reglas de responsabilidad contravencional incluidas en la LPC. Por su parte, ciertos contenidos contractuales contrarios a la nueva normativa exponen al proveedor a la declaración de nulidad de la respectiva cláusula.

El incumplimiento de los deberes de conducta que impone la nueva reglamentación del Sernac Financiero constituye infracción a la ley, y faculta para que el Sernac y los consumidores puedan deducir denuncias ante los tribunales competentes, los que aplicarán las multas correspondientes.

El monto de las multas dependerá del tipo de infracción o incumplimiento de que se trate y, específicamente, se contemplan importantes sanciones para aquellos proveedores sujetos a estándares más elevados por poseer Sello Sernac. En efecto, la actual normativa distingue diversas hipótesis:

\section{a) Mal uso del Sello Sernac}

Una primera infracción se constituye por el mal uso del Sello Sernac. En efecto, la normativa dispone que los proveedores que promocionen o distribuyan un contrato de adhesión de un producto o servicio financiero sin Sello Sernac como si lo tuviere, o que no cumplan las obligaciones establecidas en el inciso final del artículo 55 C (a propósito de la revocación del Sello Sernac), serán sancionados con multa de hasta mil unidades tributarias mensuales (artículo $55 \mathrm{D}$ ).

\section{b) Incumplimiento estándares del servicio de atención al cliente (SAC)}

Aquellos proveedores que cuenten con Sello Sernac se obligan a mantener un SAC que se encuentra regulado en la ley tanto en aspectos procedimentales como de fondo. Acorde a las exigencias legales en la materia, se contempla que el proveedor dé una respuesta fundada al reclamo del consumidor dentro de 10 días hábiles contados desde su presentación. Asimismo, el proveedor debe dar cumplimiento 
a lo señalado en la respuesta del SAC en el plazo de cinco días hábiles, contado desde la comunicación al consumidor.

En caso de incumplir las obligaciones anteriores en los plazos señalados, el Sernac debe denunciar al proveedor ante el juez de policía local competente, para que, si procediere, se le sancione con una multa de hasta cincuenta unidades tributarias mensuales, sin perjuicio del derecho del consumidor afectado para denunciar el incumplimiento de las obligaciones referidas.

\section{c) Incumplimiento de acuerdos de mediadores o sentencias de árbitros financieros}

En caso que el proveedor no cumpla con la propuesta de acuerdo de un mediador debidamente aceptada por las partes, o con la sentencia definitiva de un árbitro financiero en el plazo establecido en los artículos $56 \mathrm{D}$ o $56 \mathrm{E}$ (15 días hábiles en ambos casos), según corresponda, el Sernac deberá denunciarlo ante el juez competente para que se le sancione con una multa de hasta setecientas cincuenta unidades tributarias mensuales. Además, el Sernac podrá revocar el Sello Sernac otorgado al proveedor de productos y servicios financieros, sin que pueda éste solicitarlo nuevamente antes de transcurridos tres meses desde la revocación. Adicionalmente y tal como señala la ley, el deber de denuncia del Sernac no obsta al derecho del consumidor afectado para denunciar el incumplimiento, por parte del proveedor, de la propuesta de acuerdo o sentencia definitiva, según corresponda.

\section{d) Negativa o demora ante requerimientos de información}

El Sernac tiene facultades para requerir información a los proveedores, relativa a información básica comercial y otra documentación que permita el ejercicio de las atribuciones del Servicio. La normativa vigente dispone que la negativa o demora injustificada en la remisión de los antecedentes requeridos en virtud de este artículo (artículo 58 LPC) será sancionada con multa de hasta cuatrocientas unidades tributarias mensuales por el juez de policía local.

\section{e) Incumplimiento de disposiciones generales}

Las disposiciones del Sernac Financiero regulan una serie de otros aspectos tales como las menciones esenciales de los contratos de adhesión de este mercado, obligatoriedad de la hoja resumen, obligación de informar liquidación del crédito en ejecución, término del contrato por parte del consumidor, prohibición de envío de productos o contratos no solicitados por el consumidor, deber de informar la carga anual equivalente, prohibición de ventas atadas, regulación de mandatos y deberes de información para avalistas y codeudores solidarios, entre otras disposiciones. El incumplimiento por parte de un proveedor de estas obligaciones generales (contenidas en los artículos $17 \mathrm{~B}$ a $17 \mathrm{~J}$ ) y de los reglamentos dictados para la ejecución de estas normas, que afecte a uno o más consumidores, será 
sancionado como una sola infracción, con multa de hasta setecientas cincuenta unidades tributarias mensuales.

\section{Desafíos PENDientes EN LA MATERIA}

Los principales desafíos que se anticipan en el ámbito del Sernac Financiero son la compleja labor de educación financiera a cargo del Estado en relación con materias financieras, y la capacidad de respuesta que deberá tener el Sernac para enfrentar exitosamente la labor de otorgamiento del Sello Sernac.

\section{a) Educación Financiera}

Una reglamentación como ésta no se entiende completa sino se considera como supuesto básico e indispensable para el logro de los objetivos perseguidos que el Estado desarrolle una efectiva política de Educación Financiera, con el fin de facilitar la comprensión del público consumidor sobre aspectos relevantes en el ámbito financiero. Se trata de un mercado altamente complejo para el consumidor promedio, con una terminología de difícil alcance, con nociones que exigen un elevado nivel de abstracción y la aplicación de habilidades matemáticas por parte de la población.

Ello supone, por consiguiente, que es un rol del Estado enfrentar el desafío de generar una política de Educación Financiera de largo plazo en el país, con recursos, instrumentos y apoyos tendientes a mejorar sustancialmente la capacidad de entendimiento de los consumidores sobre los temas financieros. De otra forma, la nueva regulación no solucionará uno de los más arraigados males endémicos en nuestra sociedad: el sobreendeudamiento y la poca racionalidad en las decisiones de consumo financiero. Los proveedores de productos y servicios financieros han buscado diferenciar sus productos agrupando productos relacionados $\mathrm{u}$ ofreciendo variados términos contractuales que son difíciles de comparar para los consumidores. Se identifican en este mercado términos técnicos de difícil comprensión, contratos que obligan a los consumidores por largos períodos, y dificultades en entender los costos y beneficios de elegir entre ciertos productos o servicios financieros que pueden ir asociados a ciertas ventajas comerciales transitorias (como ofertas y promociones), lo que puede dificultar la comparación del consumidor en procurar la mejor elección según sus necesidades particulares.

El Estado (Sernac, Ministerio de Economía, y otros órganos públicos) debe necesariamente tener presente y considerar políticas efectivas para enfrentar el nivel de conocimiento práctico y de comprensión de lectura que es cada vez más bajo. El fenómeno de la alfabetización y las dificultades de entendimiento de la población se da especialmente en el ámbito financiero, donde las buenas decisiones de las personas se toman dependiendo de la capacidad de poder leer y entender determinada información. Este escenario constituye un claro desafío 
para los diseñadores de políticas públicas, que debieran buscar solucionar estas diferencias de información del mercado, e impulsar políticas de educación y de entrega de herramientas útiles a los consumidores para incentivarlos y permitirles tomar decisiones de endeudamiento responsables ${ }^{11}$. Esta Educación Financiera debiera fortalecer el conocimiento de los usuarios con miras a reducir y/o acotar la posibilidad de default o endeudamiento excesivo, considerando su capacidad de pago actual y futura, posibilitando una efectiva y útil comparación de productos financieros con miras a identificar la opción que más se ajuste a sus necesidades finales ${ }^{12}$.

\section{b) Labor de otorgamiento del Sello Sernac y costos asociados a su obtención}

Seguramente vencidos los temores e inquietudes que trae aparejada esta nueva regulación, los proveedores comenzarán a solicitar formalmente el Sello Sernac. Ello lleva aparejado el desafío a este órgano público de tener eficientes prácticas y procedimientos tendientes a asegurar la mejor revisión jurídica de los contratos de adhesión sometidos a su validación, evitando retrasos y entrabamientos que puedan afectar la imagen y ventajas que significa el Sello Sernac para los proveedores.

Desde otra perspectiva, existirá una incertidumbre y riesgo en el proveedor que desee acceder al Sello Sernac, en base -a lo menos- a dos variables: (a) los mayores costos que le significará optar por los estándares que están asociados al Sello Sernac (entre otros, los mayores costos para el financiamiento de los mecanismos de mediación y arbitraje, y el mayor uso de recursos humanos de la institución en los procedimientos relacionados con atención de clientes en los tiempos y condiciones que establece la nueva normativa, aplicación estricta de los estándares de información a los usuarios, entre otros), en relación con las ventajas esperadas de mayor demanda y preferencia de los consumidores por sobre sus competidores por la circunstancia de contar con el Sello Sernac; (b) la inseguridad que puede provocar la incertidumbre de si los contratos de adhesión sometidos a la revisión de la autoridad cumplirán adecuadamente los estándares que determine en forma privativa el Sernac sobre la correcta aplicación de la LPC. Lo anterior se suma a la inseguridad que puede provocar la pérdida del Sello Sernac, lo cual irá irremedia-

\footnotetext{
${ }^{11}$ Recientes estudios sitúan la educación y conciencia financiera en un lugar esencial para procurar el bienestar económico, ya que los mercados permiten en la actualidad que los consumidores puedan acceder a crédito con mayor facilidad que antes, pero al mismo tiempo los avances tecnológicos y una nueva oferta de productos y servicios han convertido a las operaciones bancarias modernas en un complejo sistema de difícil comprensión. En Gambrell, Donna (2003). Financial Education in a Dynamic Banking Environment. Documento de la Federal Deposit Insurance Corporation (FDIC), institucional gubernamental de Estados Unidos.

${ }^{12}$ En el documento de trabajo de la OECD (2009). Construyendo herramientas para una politica del consumidor. París, 20-21 de octubre, se identifican estas aproximaciones y vulnerabilidades de los usuarios de servicios financieros.
} 
blemente aparejado de un efecto comunicacional que afectará a la marca y prestigio del proveedor frente al público consumidor.

En este contexto, todo riesgo lleva en general a asumir -como conducta económica- una actitud de resistencia, teniendo presente que en la mayoría de las veces las personas se sienten más cómodas con un escenario conocido ${ }^{13}$. El Sello Sernac puede traer aparejado para los proveedores ciertas incertidumbres arriba apuntadas que pueden afectar los objetivos buscados por la autoridad, con la consagración de este mecanismo voluntario de adscribir a buenas prácticas. Resultará necesario que la autoridad entregue no sólo las herramientas y procedimientos expeditos para postular al Sello Sernac, sino también genere las condiciones de entorno para incentivar su uso y obtención, y establezca y difunda prácticas y estándares que permitan a los proveedores de productos y servicios financieros conocer las características y reales costos e impactos asociados al proceso de obtención del Sello Sernac.

\footnotetext{
${ }^{13}$ En los modelos económicos -y en la conducta de los actores de mercado- la toma de decisiones bajo la incertidumbre considera la aversión al riesgo como una de las actitudes más comunes e intuitivas. En CoOTER, Robert y Ulen, Thomas (2008). Derecho y Economía. México D.F.: Fondo de Cultura Económica.
} 